Available online at: http://openjournal.masda.ac.id/index.php/edumasda

Edu Masda Journal

ISSN (Print) 2597-4572 ISSN (Online) 2715-5269

\title{
GAMBARAN KERASIONALAN RESEP ANTIBIOTIK DENGAN DIAGNOSA ISPA DI POLI ANAK RUMAH SAKIT PRIKASIH JAKARTA SELATAN \\ PERIODE JANUARI - MARET 2020
}

Neneng Sri Purwanigsih", Dimas Agung Wijanarko, Ana Yuli Handayani .IKes Kharisma Persada, Jalan Pajajaran No. 1 Pamulang Tangerang Selatan Banten, 15417

\begin{tabular}{|c|c|}
\hline ARTICLE INFORMATION & $A B S T R A C T$ \\
\hline $\begin{array}{l}\text { Corresponding } \\
\text { Neneng Sri Purwanigsih } \\
\text { E-mail: neneng@masda.ac.id }\end{array}$ & \multirow{2}{*}{$\begin{array}{l}\text { Irrational drug use is a major problem in the world. Irrational prescribing } \\
\text { of drugs can be described as medically inaccurate and ineffective in } \\
\text { financing, treatment There are many studies that describe the treatment of } \\
\text { ARD (Acute Respiratory Disease) patients who tend to use antibiotics which } \\
\text { lead to overprescription and become irrational. This research was to } \\
\text { descripte of a rational antibacterial prescription with a diagnosis of upper } \\
\text { Acute Respiratory Tract Infection (ARI) at Prikasih Hospital Children's } \\
\text { Clinic. Methods for this research is descriptive method using retrospective } \\
\text { data. Samples in this study were } 380 \text { recipes. The results showed that there } \\
\text { were } 79.7 \% \text { rational recipes and } 20.3 \% \text { irrational recipes. Based on the } \\
\text { choice of drug type, cefixime is the most widely used antibiotic with a rule of } \\
3 \text { times a day. }\end{array}$} \\
\hline $\begin{array}{l}\text { Keywords: } \\
\text { - } \quad \text { Rationality } \\
\text { - } \quad \text { Antibiotic Prescription } \\
\text { - } \quad \text { ISPA } \\
\text { - } \quad \text { Children Clinical }\end{array}$ & \\
\hline $\begin{array}{l}\text { Kata Kunci: } \\
\text { - } \quad \text { Kerasionalan } \\
\text { - } \text { Resep Antibiotik } \\
\text { - ISPA } \\
\text { - Poli Anak }\end{array}$ & $\begin{array}{l}\text { Penggunaan obat yang tidak rasional adalah suatu masalah utama di dunia } \\
\text { ini. Peresepan obat yang tidak rasional bisa digambarkan sebagai tidak } \\
\text { tepanya obat secara medis dan tidak efektif dalam pembiayaan pengobatan. } \\
\text { Banyaknya penelitian yang menggambarkan penyembuhan penyakit untuk } \\
\text { pasien ISPA adalah hampir keseluruhan menggunakan antibiotik dengan } \\
\text { peresepan ysng berlebihan dan menjadi tidak rasional dalam pengobatan . } \\
\text { Tujuan penelitian ini adalah untuk mengetahui kerasionalan resep obat } \\
\text { antibiotik dengan diagnosa Infeksi Saluran Pernapasan Akut (ISPA) bagian } \\
\text { atas di Poli Anak Rumah Sakit Prikasih. Dalam penelitian ini metode yang } \\
\text { digunakan adalah metode deskriptif dengan menggunakan data retrospektif. } \\
\text { Jumlah sampel dalam penelitian ini sejumlah } 380 \text { resep. Hasil penelitian } \\
\text { menunjukkan bahwa terdapat } 79.7 \% \text { resep rasional dan } 20.3 \% \text { resep tidak } \\
\text { rasional. Berdasarkan pemilihan jenis obat, cefixime merupakan antibiotik } \\
\text { yang paling banyak digunakan dengan aturan pemakaian } 3 \text { x sehari. }\end{array}$ \\
\hline
\end{tabular}




\section{PENDAHULUAN}

Dalam pelayanan kesehatan obat merupakan salah satu faktor penting dalam pelayanan kesehatan, akan tetapi World Health Organization (WHO) memperkirakan terdapat sekitar 50\% dari seluruh penggunaan obat masih ada yang tidak tepat dalam pembuatan resep, penyiapan resep, dan penjualan obat resep dimana sekitar $50 \%$ tidak diindikasikan secara tepat untuk pasien. Penggunaan obat yang tidak tepat akan menimbulkan banyak masalah. Dimana di antaranya meliputi segi efektivitas, efek samping, interaksi obat, faktor ekonomi dan penyalahgunaan obat. Maka dalam penggunaan obat diperlukan pertimbangan yang tepat agar penggunaannya efektif dan efisien (Septi Muharni, 2014).

$$
\text { Penyakit Infeksi Saluran }
$$

Pernafasan Akut (ISPA) sering dijumpai di negara-negara berkembang, seperti di Indonesia maupun di negara-negara maju. Berdasarkan hasil Riskesdas tahun 2007 didapatkan prevalensi nasional ISPA di Indonesia adalah 25,5\%. Di Indonesia pada tahun 2013, tingkat penggunaan antibiotik pada penyakit ISPA non spesifik dan non pneumonia mencapai angka 47,80\%, Data ISPA di berbagai Provinsi di Indonesia untuk yang tertinggi adalah Nusa Tenggara Timur $(41,7 \%)$, Papua (31,1\%), Aceh (30,0\%), dan angka kejadian tertinggi ISPA menurut kelompok umur adalah umur 1-4 tahun (25,8\%), umur dibawah 1 tahun $(22,0 \%)$ dan umur 5-14 tahun $(15,4 \%)$ (Muhammad Azmi Awaluddin, 2016).

Dalam hal kerasionalan dikatakan bahwa obat yang rasional secara cakupan biomedis mencakup beberapa kriteria seperti, tepat indikasi, tepat penderita, tepat obat, tepat regimen yang meliputi dosis, frekuensi pemberian, rute pemberian dan lama pemberian, waspada efek samping. Selain itu juga kepatuhan pasien terhadap pengobatan yang dijalaninya (Septi Muharni, 2014).

Banyaknya penelitian yang menggambarkan pengobatan pasien ISPA cenderung menggunakan obat antibiotik yang menyebabkan peresepan berlebihan dan menjadi tidak rasional. (Firda Aulia S, 2018). Berdasarkan penelitian pendahuluan yang dilakukan terhadap beberapa resep di poli anak Rumah Sakit Prikasih periode 1 Januari-31 Maret 2020 dengan diagnosa ISPA, terdapat beberapa resep yang mengandung antibiotik dan antivirus serta menggunakan dosis yang kurang tepat. Sehingga penulis tertarik untuk mengetahui tingkat kerasionalan resep antibiotik di poli anak Rumah Sakit Prikasih dengan diagnosa ISPA.

\section{METODE}

Dalam penelitian ini metode yang digunakan adalah menggunakan Metode 
Deskriptif yaitu penelitian yang menggambarkan, menguraikan hasil pengamatan dan data yang digunakan adalah data lampau yaitu bersifat retrospektif. Penelitian ini dilakukan di Instalasi Farmasi Rawat Jalan Rumah Sakit Prikasih Jakarta Selatan pada bulan Maret sampai Juni tahun 2020.

Populasi dalam penelitian ini adalah seluruh resep poli anak yang diterima di Instalasi Farmasi Rawat Jalan Rumah Sakit Prikasih Jakarta Selatan Periode 1 Januari 2019 - 31 Maret 2020. Jumlah populasi di Instalasi Farmasi Rawat Jalan Rumah Sakit Prikasih Periode 1 Januari 2019 - 31 Maret 2020 sejumlah 7.729 resep. Sampel dalam penelitian ini adalah resep rawat jalan di poli anak dengan diagnosa ISPA pada tanggal 1 Januari 2020 - 31 Maret 2020.

Teknik pengambilan sampel yang digunakan pada penelitian ini adalah simple random sampling yaitu pengambilan sampel penelitian dengan cara mengundi elemen/anggota populasi (Sugiono, 2015). Pengumpulan data ini dilakukan dengan cara mengumpulkan data sekunder, yaitu data rekam medik pasien rawat jalan di poli anak Rumah Sakit Prikasih dengan diagnosa ISPA

\section{HASIL}

\section{Karakteristik Pasien Berdasarkan Usia}

Dari data rekam medis berdasarkan usia didapatkan bahwa pasien dengan usia anak dengan rentang 0 - 3 tahun sebanyak 197 pasien (51.84\%), usia dengan rentang 4 - 6 tahun sebanyak 89 pasien (23.42\%), usia dengan rentang 7 - 9 tahun sebanyak 48 (12.63\%), usia dengan rentang 10 - 13 tahun sebanyak 28 pasien (7.37\%), rentang usia 14-18 tahun sebanyak 18 pasien $(4.74 \%)$. Untuk lebih jelas dapat dilihat pada tabel 1 dibawah ini :

Tabel 1 Resep Berdasarkan Usia

\begin{tabular}{ccc}
\hline Umur & Jumlah & \% \\
\hline 0 - 3 Tahun & 197 & 51.84 \\
4 - 6 Tahun & 89 & 23.42 \\
6 - 9 Tahun & 48 & 12.63 \\
10 - 13 Tahun & 28 & 7.37 \\
14 - 18 Tahun & 18 & 4.74 \\
\hline Total & $\mathbf{3 8 0}$ & $\mathbf{1 0 0}$ \\
\hline
\end{tabular}

Karakteristik Pasien Berdasarkan Jenis Kelamin

Dari data rekam medis berdasarkan jenis kelamin didapatkan bahwa pasien dengan jenis kelamin laki laki sebanyak 206 pasien (54.2 \%) dan perempuan sebanyak 174 pasien 
(45.8\%). Untuk lebih jelas dapat dilihat pada Tabel 2 dibawah ini :

Tabel 2 Resep Berdasarkan Jenis Kelamin

\begin{tabular}{ccc}
\hline Jenis Kelamin & Jumlah & \% \\
\hline Laki - laki & 206 & 54.2 \\
Perempuan & 174 & 45.8 \\
\hline Total & $\mathbf{3 8 0}$ & $\mathbf{1 0 0}$
\end{tabular}

Karakteristik Pasien berdasarkan berat badan

Dari Data rekam medis berdasarkan berat badan didapatkan bahwa pasien dengan berat badan $0-10 \mathrm{~kg}$ sebanyak 70 pasien ( $18.4 \%$ ), $11-20 \mathrm{~kg}$ sebanyak 161 pasien ( $42.4 \%$ ), $21-30 \mathrm{~kg}$ sebanyak 91 pasien ( $23.9 \%$ ), $31-40 \mathrm{~kg}$ sebanyak 41 pasien $(10.8 \%), 41-50 \mathrm{~kg}$ sebanyak 17 pasien $(4,5 \%)$. Untuk lebih jelas dapat dilihat pada Tabel 3:

Tabel 3 Resep Berdasarkan Berat Badan

\begin{tabular}{clc}
\hline Demografi & Jumlah & \% \\
\hline $0-10 \mathrm{~kg}$ & 70 & 18.4 \\
$11-20 \mathrm{~kg}$ & 161 & 42.4 \\
$21-30 \mathrm{~kg}$ & 91 & 23.9 \\
$31-40 \mathrm{~kg}$ & 41 & 10.8 \\
$41-50 \mathrm{~kg}$ & 17 & 4.5 \\
\hline Total & $\mathbf{3 8 0}$ & $\mathbf{1 0 0}$ \\
\hline
\end{tabular}

Pilihan Jenis Antibiotik Dan Dosis Obat Pilihan Jenis Antibiotik Dan Dis Obat

Dari data rekam medis untuk terapi antibiotik obat ISPA di Instalasi
Farmasi Rawat Jalan Rumah Sakit didapatkan bahwa antibiotik yang digunakan pada pasien. Untuk lebih jelas dapat dilihat pada Tabel 4 sebagai berikut:

Tabel 4 Jenis Antibiotik Dan Dosis Obat

\begin{tabular}{cccl}
\hline Nama obat & Dosis obat & Jumlah & \% \\
\hline Cefixime & $0.01-0.1 \mathrm{~g}$ & 239 & 62.9 \\
Cefixime & $0.101-0.2 \mathrm{~g}$ & 22 & 5.8 \\
AMOXICILLIN & $0.05-0.2 \mathrm{~g}$ & 43 & 11.3 \\
AMOXICILLIN & $0.201-0.5 \mathrm{~g}$ & 10 & 2.7 \\
AZITHROMYCIN & $0.05-0.1 \mathrm{~g}$ & 10 & 2.6 \\
AZITHROMYCIN & $0.101-0.2 \mathrm{~g}$ & 12 & 3.2 \\
AMOXICILLIN+KLA & $0.125 \mathrm{~g}$ & 2 & 0.5 \\
VULANAT & & & \\
AMOXICILLIN+KLA & $0.250 \mathrm{~g}$ & 14 & 3.7 \\
VULANAT & & & \\
CEFADROXIL & $0.1-0.2 \mathrm{~g}$ & 10 & 2.6 \\
CEFADROXIL & $0.201-0.3 \mathrm{~g}$ & 10 & 2.6 \\
COTRIMOXAZOLE & $0.240 \mathrm{~g}$ & 8 & 2.1 \\
SYR & & & \\
\hline TOTAL & & $\mathbf{3 8 0}$ & $\mathbf{1 0 0}$ \\
\hline
\end{tabular}


Aturan Pemakaian Obat

Aturan Pemakaian Obat

Dari data rekam medis untuk terapi antibiotik obat ISPA di Instalasi Farmasi Rawat Jalan Rumah Sakit didapatkan bahwa pasien yang mendapatkan aturan pakai $1 \quad \mathrm{x}$ sehari sebanyak 21 pasienn ( $5.5 \%$ ), 2 x sehari sebanyak 112 pasien ( $29.5 \%$ ), 3 x sehari sebanyak 247 pasien ( $65 \%)$. Untuk lebih jelas dapat dilihat pada Tabel 5 sebagai berikut. :

Tabel 5 Aturan Pemakaian Obat

\begin{tabular}{clcc}
\hline NAMA OBAT & ATURAN & JUMLAH & \% \\
& PEMAKAIAN & & \\
\hline Cefixime & $3 \times$ sehari & 192 & 50.5 \\
AMOXICILLIN & $2 \times$ sehari & 119 & 31.3 \\
AZITHROMYCIN & 3 x sehari & 30 & 7.9 \\
AMOXICILLIN+ & 1 x sehari & 12 & 3.2 \\
KLAVULANAT & 3 x sehari & 9 & 2.3 \\
CEFADROXIL & 3 x sehari & 12 & 3.2 \\
COTRIMOXAZOLE SYR & $2 \times$ sehari & 1 & 0.3 \\
\hline TOTAL & 2 x sehari & 5 & 1.3 \\
\hline
\end{tabular}

Resep

\section{Kerasionalan Resep}

Dari data rekam medis untuk gambaran tingkat kerasionalan resep dengan diagnosa Infeksi Saluran
Pernapasan Akut (ISPA) di Poli anak Rumah Sakit Prikasih periode1 Januari 31 Maret, untuk lebih jelas dapat dilihat pada Tabel 6 sebagai berikut:

Tabel 6 Tingkat Kerasionalan Resep

\begin{tabular}{ccc}
\hline Tingkat & Jumlah & \% \\
\hline Rasional & 303 & 79.7 \\
Tidak Rasional & 77 & 20.3 \\
\hline Total & $\mathbf{3 8 0}$ & $\mathbf{1 0 0}$ \\
\hline
\end{tabular}




\section{PEMBAHASAN}

\section{Karakteristik Pasien}

Berdasarkan data pada Tabel 1 didapatkan jumlah pasien di poli anak Rumah Sakit Prikasih dengan diagnosa ISPA sebanyak 380 pasien, didapatkan bahwa pasien dengan rentang usia terbanyak yaitu 0-3 tahun sebanyak 197 pasien (51.8 \%). Rentang Berat badan anak terbanyak yaitu 11 - 20kg yaitu terdapat 161pasien (42.4\%).

Berdasarkan data pada Tabel 2 untuk jenis kelamin didapatkan data bahwa pasien dengan jenis kelamin terbanyak, yaitu laki - laki sebanyak 206 pasien $(54.2 \%$ ).

\section{Pilihan Jenis Antibiotik Dan Dosis Obat}

Berdasarkan Tabel 4 jenis antibiotik yang digunakan, menunjukkan bahwa antibiotik yang paling banyak digunakan adalah cefixime dengan presentase sebesar $62.9 \%$ dan dalam rentang dosis $0.01-0.1 \mathrm{~g}$.

\section{Aturan Pemakaian Obat}

Berdasarkan hasil penelitian terapi antibiotik obat ISPA di Instalasi Farmasi Rawat Jalan Rumah Sakit didapatkan bahwa pasien yang mendapatkan aturan pakai terbanyak yaitu 3 x sehari sebanyak 247 pasien (65\%) dengan dosis cefixime terbanyak $0.01-0.1$ gram sebesar $50.5 \%$. Pada penelitian ini menunjukkan bahwa kerasionalan resep berdasarkan aturan pemakaiannya dapat dikatakan rasional. Berikut contoh resep yang rasional terdapat pada resep nomor 73 tanggal 7 Januari 2020 yaitu pemakaian obat cefixime dalam resep racikan sebesar 0.09 gram / hari dengan berat badan $12 \mathrm{~kg}$ sesuain dnegan buku panduan terstandar yaitu $1.5-3 \mathrm{mg} / \mathrm{kg}$.

\section{Kerasionalan Resep}

Pada penelitian kali ini, terdapat resep yang rasional sebanyak 303 resep (79.7\%). Terdapat resep yang tidak rasional karena tidak sesuai dengan dosis yang terdapat pada buku panduan terstandar. Berikut contoh resep yang tidak rasional seperti pada resep nomor 134, tanggal 21 Maret 2020 dengan usia anak 1 tahun dan memiliki berat badan $9.7 \mathrm{~kg}$, terdapat obat Cefixime sirup dengan dosis $200 \mathrm{mg} /$ hari yang seharusnya pemakaian maksimum yaitu sebanyak 58.2 $\mathrm{mg} /$ harinya.

Penggunaan obat secara rasional dapat diartikan sebagai penggunaan obat yang disesuaikan dengan kebutuhan klinis pasien, baik dalam jumlah maupun waktu yang memadai. Penggunaan obat harus sesuai dengan penyakit, oleh karena itu diagnosis yang ditetapkan harus tepat patofisiologi penyakit, keterkaitan farmakologi obat dengan patofisiologi penyakit dan dosis yang diberikan dan waktu pemberian yang tepat, serta evaluasi dan efektivitas dan toksisitas obat tersebut, 
ada tidaknya kontraindikasi serta biaya yang dikeluarkan harus sesuai dengan kemampuan pasien tersebut. (Ami A. Pratiwi, 2012 ).

Pengobatan rasional adalah pasien menerima pengobatan yang sesuai dengan kebutuhan klinis mereka, dalam dosis yang sesuai dengan kebutuhan individual, untuk jangka waktu yang tepat dan dalam biaya terapi yang terendah bagi pasien maupun komunitas mereka ( Ratna, 2017 ).

Dalam penelitian ini, kerasonalan resep dapat ditentukan ketiga parameter yaitu, dosis obat, aturan pakai, dan jenis obat. Jika salah satu diantara ketiga parameter tersebut tidak terpenuhi, maka resep tersebut dikatakan resep yang tidak rasional.

\section{KESIMPULAN}

$\begin{array}{ccc}\text { Didapatkan } & \text { hasil bahwa } \\ \text { karakteristik pasien } & \text { bsebagian besar }\end{array}$ responden berusia 0-3 tahun sebanyak 197 pasien $(51.8 \%)$, jenis kelamin laki - laki sebanyak 206 pasien (54.2\%), pemilihan jenis obat dan dosis yang digunakan adalah Cefixime dosis terbanyak $0.01-0.1$ gram, aturan pemakaian menunjukkan bahwa $100 \%$ sudah rasional, dimana cara pemakaian yang terbanyak 3 x sehari, serta hasil bahwa secara jenis obat, dosis dan aturan pakai menunjukkan resep yang rasional adalah $79,7 \%$.

\section{DAFTAR PUSTAKA}

Aprilia Tri Ardyanti. Evaluasi Rasionalitas Penggunaan Antibiotik pada Pasien Anak Diare Akut di Instalasi Rawat Inap RSUD Kardinah Kota Tegal Periode 2016. Karya Tulis Ilmiah. Jakarta: Fakultas Farmasi Universitas Setia Budi Surakarta. 2018.

Firda Aulia S. Pola Evaluasi Rasionalitas Penggunaan Antibiotik pada Pasien Infeksi Saluran Pernapasan Atas Akut (ISPaA) di Puskesmas Dirgahayu Kabupaen Kota Baru Kalimantan Selatan Skripsi. Jakarta: Fakultas Farmasi Universitas Muhammadiyah Surakarta. 2018.

Ismaya, N. A., Romlah, S. N., Fatulloh, R. S. A., Ratnaningtyas, T. O., \& Hasanah, N. (2020). Interpretasi Kepuasan Konsumen Terhadap Pelayanan Obat Tanpa Resep Terhadap Kepuasan Konsumen. Edu Masda Journal, 4(2), 95-107.

Gadis Fujiastuti. Evaluasi Drug Related Problems (DRPs) Infeksi Saluran Pernapasan Akut (ISPA) pada Pasien Pediatri di Instalasi Rawat Inap Salah Satu Rumah Sakit Daerah Bangka. Skripsi. Jakarta: Fakultas Kedokteran dan Ilmu Kesehatan Program Studi Farmasi UIN Syarif Hidayatullah Jakarta. 2016.

Nurul Habibah. Analisis Rasionalitas Peresepan Obat di Apotek Rumah Sakit X pada Bulan Maret Tahun 2016. Skripsi. Jakarta: Fakultas Kedokteran Universitas Yarsi. 2017.

Maftu Khatul Janah. Evaluasi Rasionalitas Obat Antihipetensi pada Pasien 
Anak Geriatri di Instalasi Rawat Inap RSUD Kardinah Kota Tegal Periode 2016. Karya Tulis Ilmiah. Jakarta: Fakultas Farmasi Universitas Setia Budi Surakarta. 2018.

Muhammad Azmi Awaluddin. Pola Ketepatan Terapi Antibiotik pada Pasien Infeksi Saluran Pernapasan Akut (ISPA) Usia Anak di Puskesmas Ciputat Timur Februari 2015. Skripsi. Jakarta: Fakultas Kedokteran dan Ilmu Kesehatan UIN Syarif Hidayatullah Jakarta. 2016.

Nurul Habibah. Analisis Rasionalitas Peresepan Obat di Apotek Rumah Sakit X pada Bulan Maret Tahun 2016. Skripsi. Jakarta: Fakultas Kedokteran Universitas Yarsi. 2017.

Ratna Sari Dewi. Rasionalitas Penggunaan Obat Demam Tifoid di Instalasi Rawat Inap RSUD Dr. Moewardi. Karya Tulis Ilmiah. Jakarta: Fakultas Farmasi Universitas Setia Budi Surakarta. 2017.

Salmahyani Pulungan. Gambaran Penggunaan Obat Rasional untuk Penyakit ISPA Non Pneumonia di Puskesmas Kuala Bali Kabupaten Serdang Bedagai. Karya Tulis Ilmiah. Medan: Fakultas Farmasi dan Kesehatan Institut Kesehatan Helvetia. 2019.

Septi Muharni., dkk. Rasionalitas Penggunaan Antibiotik Pada Pasien ISPA Pada Salah Satu Puskesmas di Kota Pekanbaru. Jurnal Penelitian Farmasi Indonesia 3;2014

Yani Mulyani. Evaluasi Rasionalitas Penggunaan Obat Tukak Peptik pada Pasien Tukak Peptik di Instalasi
Rawat Inap RSUD Pasar Minggu Jakarta. Skripsi. Jakarta: Fakultas Farmasi Institut Sains dan Teknologi Nasional. 2019. 

